\title{
Predictive value of tumor mutation burden (TMB) with targeted next-generation sequencing in immuno- checkpoint inhibitors for non-small cell lung cancer (NSCLC)
}

\author{
Xiaoting Ma, Yujian Zhang, Shan Wang, Jing Yu凶 \\ Cancer Center, Beijing Friendship Hospital, Capital Medical University, No. 95 Yong An Road, Xi Cheng District, Beijing, 100050, China. \\ $\triangle$ Corresponding author: Cancer Center, Beijing Friendship Hospital, Capital Medical University, No. 95 Yong An Road, Xicheng District, Beijing, 100050 , \\ China. Phone: +86-10-63139326, Fax: +86-10-63139326. E-mail: yujing026@ccmu.edu.cn. \\ (C) The author(s). This is an open access article distributed under the terms of the Creative Commons Attribution License (https://creativecommons.org/licenses/by/4.0/). \\ See http://ivyspring.com/terms for full terms and conditions.
}

Received: 2020.05.12; Accepted: 2020.11.03; Published: 2021.01.01

\begin{abstract}
Background: To evaluate the clinical predictive value of tumor mutation burden (TMB) for immune checkpoint inhibitor $(\mathrm{ICl})$ therapy in patients with non-small cell lung cancer (NSCLC).

Method: As of 15 February 2020, PubMed, PMC and EMBASE databases as well as the American society of clinical oncology (ASCO) and European society of medical oncology (ESMO) databases were searched. The Mantel-Haenszel or inverse variance weighted fixed-effects model $\left(I^{2} \leq 50 \%\right)$ or random-effects model $\left(I^{2}>\right.$ $50 \%$ ) were used to evaluate OR and its $95 \% \mathrm{Cl}$ of objective response rate (ORR) and disease control rate (DCR), as well as $\mathrm{HR}$ and its $95 \% \mathrm{Cl}$ of progression-free survival (PFS) and overall survival (OS). In addition, we did publication bias, heterogeneity analysis, sensitivity analysis and subgroup analysis. And quality of the studies included and the level of evidence for outcome measures were evaluated.

Results: 14 studies involving 2872 patients were included. The ORR (OR 3.52, 95\%Cl 2.32-5.35, $p<0.00001$ ), DCR (OR 3.26, 95\%Cl 1.91-5.55, $p<0.0001)$, PFS (HR 0.81, 95\%Cl 0.74-0.89, $p<0.00001$ ) and OS (HR 0.83, $95 \% \mathrm{Cl} 0.74-0.94, p=0.002$ ) of ICl therapy in the high TMB group were all superior to those in the low TMB group.

Conclusions: TMB is a promising biomarker, which can predict the efficacy of ICl therapy in advanced NSCLC patients, included ORR, DCR, PFS and OS.
\end{abstract}

Key words: disease control rate, immune checkpoint inhibitor, NSCLC, objective response rate, overall survival, progression-free survival, tumor mutation burden

\section{Introduction}

Immune checkpoint inhibitor (ICI) therapy, including immunomonoclonal antibodies against cytotoxic T lymphocyte-associated protein 4 (CTLA4), programmed cell death 1 (PD-1), or programmed death ligand 1 (PD-L1) antibodies, is a monoclonal antibody that negatively regulates $\mathrm{T}$ cell function [1]. ICI has been approved for the therapy of many different types of cancer, including non-small cell lung cancer (NSCLC), melanoma, renal cell cancer, bladder cancer, and head and neck squamous cell carcinoma [1]. Recently more and more predictive biomarkers have been used in immunotherapy research, such as tumor mutation burden (TMB), programmed cell death ligand 1 (PD-L1), and mismatch repair defect (dMMR)/microsatellites Instability (MSI) [2,3]. Currently, PD-L1 and dMMR/ MSI have been approved for clinical use [4]. TMB refers to the total number of substitution and insertion/deletion mutations per megabase in the exon coding region of the gene being evaluated in the tumor cell genome [5]. Although it has not yet been approved for clinical use, there is much evidence to support the clinical predictive value of TMB. First, tumor cells are genetically unstable and have high 
levels of somatic mutations, which may generate many new antigens, which activate $\mathrm{T}$ lymphocyte proliferation and kill tumor cells [6]. In addition, the increase in neoantigen production is expected to make tumor cells more immunogenic, thereby increasing their response to immunotherapy [4]. Studies have shown that TMB has many advantages over other biomarkers. First, it can be obtained in the blood, which may be an advantage in cases where tumor tissue specimens cannot be obtained [7]. Second, compared to PD-L1 which can only predict the response of PD-1 / PD-L1 inhibitors, TMB can predict the response of multiple immunotherapies, including PD-1 / PD-L1 inhibitors, anti-CTLA4 antibodies (such as ipilimumab) and adoptive cell transfer therapy $[8,9,10]$.

The incidence of somatic mutations in different types of tumors varies widely, with NSCLC having the highest mutation frequency, ranging from 0.1 to $100 \mathrm{mut} / \mathrm{Mb}$ [11]. Through retrospective analysis, Rizvi [12] found that the efficacy of NSCLC patients for ICI therapy was related to the TMB threshold. NSCLC patients with high TMB thresholds had better efficacy and higher survival rates for NSCLC patients with low TMB. Klempner [13] also found that the TMB cut-off value of $10 \mathrm{mut} / \mathrm{Mb}$ can predict the efficacy of ICI in patients with NSCLC, and patients with higher TMB thresholds have longer progressionfree survival (PFS). Most NSCLC studies using targeted Next Generation Sequencing (NGS) indicate that the cut-off value of TMB fluctuates around 10 mut/ $\mathrm{Mb}$.

Although many studies have revealed the predictive value of TMB for ICI therapy in NSCLC patients, some studies have reported negative results, especially in terms of long-term survival. This may be related to the fact that TMB has not received widespread attention and related research is less. In addition, the study population and immunotherapy regimens included in related studies are different, which may lead to different prediction results. In this study, we systematically reviewed and analyzed the relevant literature on the predictive value of TMB in NSCLC immunotherapy, in order to summarize the predictive effect of TMB on ICI therapy in patients with NSCLC.

\section{Methods}

\section{Search strategy}

As of February 15, 2020, electronic searches were performed on PubMed, PMC and EMBASE databases, as well as the American Society of Clinical Oncology (ASCO) and European Medical Oncology (ESMO) databases. The detailed search strategy is shown in
Figure 1.The search term was as follows: (PD-1 OR PD-L1 OR CTLA-4 OR Ipilimumab OR Tremelimumab OR Nivolumab OR Pembrolizumab OR Lambrolizumab OR Atezolizumab OR Avelumab OR Durvalumab OR "immune checkpoint inhibitor" OR "immune checkpoint inhibitors" OR "ICI" OR "ICIs" OR "immune checkpoint blocker" OR "immune checkpoint blockers" OR "ICB" OR "ICBs") AND (mutation burden OR mutational burden OR mutation load OR mutational load OR TMB OR TML) AND ("Next-Generation Sequencing" OR "Next Generation Sequencing" OR "Sequencing, NextGeneration") AND ("Non-Small Cell Lung Cancer" OR "Non-Small Cell Lung Cancer" OR "NSCLC" OR "Carcinoma, Non-Small Cell Lung" OR "Non-Small Cell Lung Carcinoma" OR "Non-Small-Cell Lung Carcinoma" OR “Non-Small-Cell Lung Carcinomas" OR "Lung Carcinoma, Non-Small-Cell" OR "Lung Carcinomas, Non-Small-Cell" OR "Carcinoma, Non-Small Cell Lung" OR "Carcinomas, Non-SmallCell Lung"). We searched all potentially relevant studies and reviewed the references in the final included articles to find possible missing studies.

\section{Inclusion criteria}

The included studies should meet the following inclusion criteria: (1) Studies include TMB testing, the correlation analysis between TMB and efficacy evaluation of therapy of NSCLC patients with ICI (anti-CTLA-4, anti-PD-1, anti-PD-L1), and use the targeted NGS to calculate the cut-off value of TMB; (2) Evaluation indicators include the number of patients who achieved the objective response rate (ORR) and disease control rate (DCR) in the high TMB group and the low TMB group or hazard ratios (HR) and their 95\% confidence intervals ( $95 \% \mathrm{CI}$ ) of progression-free survival (PFS) and overall survival (OS) are given in the article; (3) The number of people achieving ORR is the sum of complete response (CR) and partial response (PR), and the number of people achieving DCR is the sum of CR, PR and stable disease (SD).

\section{Data extraction}

Two independent researchers extracted data from the included studies based on the preferred report project (PRISMA) for systematic evaluation and meta-analysis. All inconsistencies were resolved with the unanimous consent of all researchers. Information collected from these studies includes title, first author, publication year, number of patients, region, immunotherapy protocol, assessable TMB sample size, TMB cut-off value, number of people achieving ORR and DCR, HR and 95\% CI of PFS and OS. 


\section{Quality assessment}

The Newcastle ottawa scale (NOS) was used to assess the quality of all included studies. The overall score ranges from 0 to 9 , with 8-9 indicating high quality, 5-7 indicating medium quality, and studies below 5 indicate poor quality. GRADE is used to assess the level of evidence for all analysis results, which is classified as high quality, medium quality, low quality and very low quality.

\section{Statistical analysis}

Statistical analysis was performed using Review Manager 5.3 and Forest plots were made. The main end point of the meta-analysis was to compare the ICI efficiency between the high TMB group and the low TMB group, and the evaluation indicators were OR and its $95 \%$ CI of ORR and DCR, and HR and its 95\% CI of PFS and OS. State 12.0 was used to evaluate publication bias based on Begg's and Egger's tests. Heterogeneity between studies is represented by Cochrane's $\mathrm{X}^{2}$ statistics and the inconsistency statistic $\left(\mathrm{I}^{2}\right)$. We consider $\mathrm{I}^{2}<50 \%$ as low-level heterogeneity and $\mathrm{I}^{2}>50 \%$ as significant heterogeneity. When $\mathrm{I}^{2}<$ $50 \%$, the fixed effect model was used. When $\mathrm{I}^{2}>$ is
$50 \%$, the random effects model is used. In addition, we used sensitivity analysis to test the stability of the results. In order to further explore the predictive value of TMB on the effect of immunotherapy, subgroup analysis was performed by region and immunotherapy protocol. In all included studies, $p<$ 0.05 was considered statistically significant.

\section{Results}

\section{Characteristics of the included studies}

Figure 1 shows the flow chart of this study. A total of 2043 records were retrieved through a database search. After excluding duplicate articles, 488 articles were eligible for inclusion and 442 reviews were deleted. The full text of the remaining 46 articles was then reviewed, and 14 studies [7,14-26] involving 2872 patients were finally included in the metaanalysis (Table 1). In these studies, 12 studies were for patients in western countries, 2 studies were for patients in Asian countries. And 10 studies were treated with anti-PD-1/PD-L1 monotherapy, 4 cohorts were treated with anti-PD-1/anti-PD-L1 combined with anti-CTLA-4 therapy.

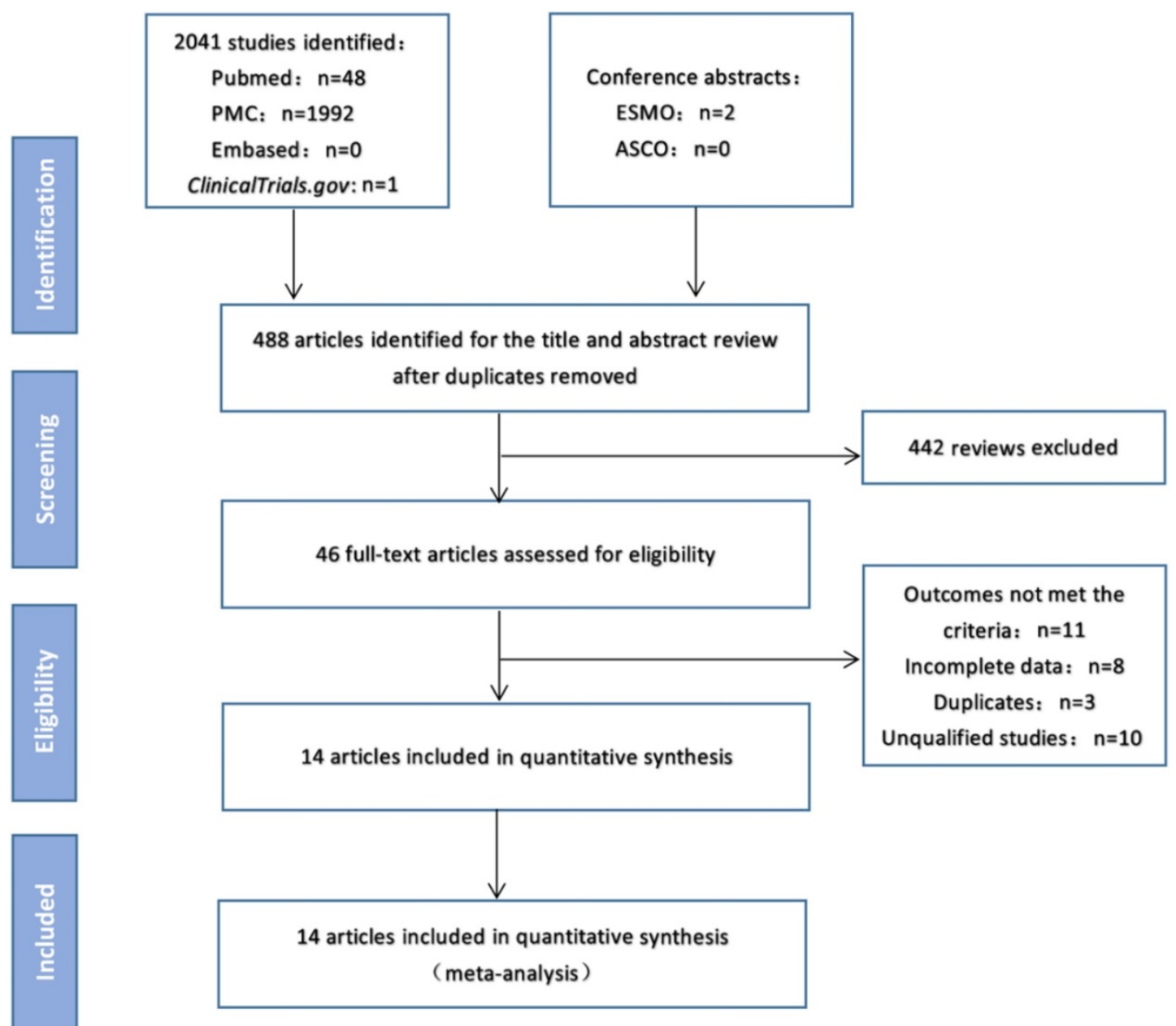

Figure 1. Study flow diagram. 
Table 1. Main characteristics of studies included in the meta-analysis

\begin{tabular}{|c|c|c|c|c|c|c|c|}
\hline Author & Time & Line of treatment & $\begin{array}{l}\text { Sample size evaluable } \\
\text { for TMB }\end{array}$ & Immunotherapy regimen & Area & TMB cut-off point & Outcomes \\
\hline Rizvi & 2018 & $\geq 1$ st-line & 240 & Anti-PD1/PD-L1 & Western & $10 \mathrm{Mut} / \mathrm{Mb}$ & PFS \\
\hline Alborelli & 2019 & 2nd-line & 76 & Anti-PD-1+Anti-CTLA4 & Western & $9 \mathrm{Mut} / \mathrm{Mb}$ & ORR, DCR, PFS, OS \\
\hline Ready & 2019 & 1st-line & 98 & Anti-PD-1+Anti-CTLA4 & Western & $10 \mathrm{Mut} / \mathrm{Mb}$ & ORR, DCR, PFS \\
\hline Paz-ares & 2018 & 1st-line & 151 & Anti-PD-1+Anti-CTLA4 & Western & $10 \mathrm{Mut} / \mathrm{Mb}$ & ORR \\
\hline Wang & 2019 & $\geq 1$ st-line & 50 & Anti-PD1/PD-L1 & Asian & $6 \mathrm{Mut} / \mathrm{Mb}$ & ORR, PFS \\
\hline Chae & 2018 & $\geq 1$ st-line & 72 & Anti-PD1/PD-L1 & Western & $15 \mathrm{Mut} / \mathrm{Mb}$ & PFS, OS \\
\hline Chae & 2019 & $\geq 1$ st-line & 20 & Anti-PD1/PD-L1 & Western & Not given & PFS, OS \\
\hline Gandara (POPLAR) & 2018 & $\geq 2$ nd-line & 105 & Anti-PD-L1 & Western & 16 mutations & PFS, OS \\
\hline Gandara (OAK) & 2018 & $\geq 2$ nd-line & 324 & Anti-PD-L1 & Western & 16 mutations & PFS, OS \\
\hline Fang & 2019 & $\mathrm{~N} / \mathrm{A}$ & 75 & Anti-PD-1/PD-L1 & Asian & $10 \mathrm{Mut} / \mathrm{Mb}$ & ORR, DCR, PFS \\
\hline Reck & 2019 & N/A & 1004 & Anti-PD-1+Anti-CTLA4 & Western & $10 \mathrm{Mut} / \mathrm{Mb}$ & OS \\
\hline Goodman & 2017 & $\geq 1$ st-line & 36 & Anti-PD-1/PD-L1 & Western & $20 \mathrm{Mut} / \mathrm{Mb}$ & ORR, PFS, OS \\
\hline Kowanetz & 2017 & 1st-line & 102 & Anti-PD-1/PD-L1 & Western & 13.5 Mut/Mb & PFS, OS \\
\hline Kowanetz & 2017 & $\geq 2$ nd-line & 371 & Anti-PD-1/PD-L1 & Western & 17.1 Mut/Mb & PFS, OS \\
\hline Roszik & 2016 & $\mathrm{~N} / \mathrm{A}$ & 29 & Anti-PD-1/PD-L1 & Western & 100 mutations & ORR, DCR \\
\hline Genentech & 2020 & 1st-line & 119 & Anti-PD-1/PD-L1 & Western & $16 \mathrm{Mut} / \mathrm{Mb}$ & PFS \\
\hline
\end{tabular}

Abbreviations: TMB: Tumor mutation burden; ORR: Objective response rate; DCR: Disease control rate; PFS: Progression-free survival; OS: Overall survival.

\section{Quality assessment of included studies}

NOS results indicate that 5 studies were high quality and 9 studies were medium quality, which ensures the relatively high quality of the study and improves the reliability of the meta-analysis (Table 2).

Table 2. Quality assessment of studies included in the meta-analysis using Newcastle Ottawa Scale (NOS)

\begin{tabular}{llllllllll}
\hline Study & S1 & S2 & S3 & S4 & C & O1 & O2 & O3 & $\begin{array}{c}\text { Total } \\
\text { score }\end{array}$ \\
\hline rizvi2018 & 0 & 1 & 1 & 1 & 1 & 1 & 1 & 1 & 7 \\
alborelli2019 & 1 & 1 & 1 & 1 & 2 & 1 & 1 & 1 & 9 \\
ready2019 & 1 & 1 & 1 & 1 & 2 & 0 & 1 & 1 & 8 \\
paz-ares2018 & 1 & 1 & 1 & 1 & 2 & 1 & 1 & 1 & 9 \\
wang2019 & 1 & 1 & 1 & 1 & 2 & 1 & 1 & 1 & 9 \\
chae2018 & 1 & 1 & 1 & 1 & 0 & 1 & 1 & 1 & 7 \\
chae2019 & 1 & 1 & 1 & 1 & 0 & 1 & 1 & 1 & 7 \\
gandara2018 & 1 & 1 & 1 & 1 & 1 & 1 & 1 & 1 & 8 \\
fang2019 & 1 & 1 & 1 & 1 & 0 & 1 & 1 & 1 & 7 \\
reck2019 & 1 & 1 & 1 & 1 & 0 & 1 & 1 & 1 & 7 \\
goodman2017 & 1 & 1 & 1 & 1 & 0 & 1 & 1 & 1 & 7 \\
kowanetz2017 & 1 & 1 & 1 & 1 & 0 & 1 & 1 & 1 & 7 \\
roszik2016 & 1 & 1 & 1 & 1 & 1 & 1 & 1 & 1 & 7 \\
genentech2020 & 1 & 1 & 1 & 1 & 0 & 0 & 1 & 1 & 6 \\
\hline
\end{tabular}

S1: Representativeness of the exposed cohort; S2: Selection of the non-exposed cohort; S3: Ascertainment of exposure; C: Outcome of interest not present at start of study; O1: Comparability of cohorts; O2: Assessment of outcome; O3: Follow-up long enough; O4: Adequacy of follow up of cohorts.

\section{Overall response rate (ORR) and disease control rate (DCR)}

In 7 studies including 515 NSCLC patients, we evaluated the relationship between TMB and ORR for ICI therapy. Compared with the low TMB group, the ORR of ICI therapy was significantly higher in the high TMB group (OR 3.52, 95\%CI 2.32-5.35, $p<$ $0.00001)$, and there was no heterogeneity $\left(\mathrm{I}^{2}=0 \%, \mathrm{P}=\right.$ 0.72) (Fig. 2A). Subgroup analysis showed (Fig. 2B), in both Asian (OR 3.39, 95\%CI 1.34-8.57, $p=0.01$ ) and western (OR 3.55, 95\%CI 2.23-5.68, $p<0.00001$ ) groups, the ORR of patients with ICI therapy in the high TMB group was higher than those in the low TMB group. In the groups of anti-PD-1/anti-PD-L1 therapy (OR 4.02, 95\%CI 1.78-9.08, $p=0.0008$ ) and anti-PD-1/anti-PD-L1 combined with anti-CTLA-4 therapy (OR 3.35, 95\%CI 2.06-5.46, $p<0.00001$ ), ORR for ICI therapy was higher for patients in the high TMB group than those in the low TMB group.

In 4 studies involving 278 NSCLC patients, we evaluated the relationship between TMB and DCR for ICI therapy. DCR for ICI therapy in the high TMB group was significantly higher than that in the low TMB group (OR 3.26, 95\%CI 1.91-5.55, $p<0.0001$ ), and there was no heterogeneity $\left(\mathrm{I}^{2}=7 \%, \mathrm{P}=0.36\right)$ (Fig. $3 \mathrm{~A})$. According to the subgroup analysis (Fig. 3B), in both Asian (OR 3.81, 95\% CI 1.32-10.65, $p=0.01$ ) and western (OR 3.10, 95\% CI 1.68-5.74, $p=0.0003$ ) groups, DCR for ICI therapy of patients in the high TMB group was higher than those in the low TMB group. In the groups of anti-PD-1/anti-PD-L1 therapy (OR 5.36, 95\%CI 2.05-13.99, $p=0.0006$ ) and anti-PD-1/ anti-PD-L1 combined with anti-CTLA-4 therapy (OR $2.59,95 \%$ CI 1.36-4.94, $p=0.004)$, DCR for ICI therapy was higher for patients in the high TMB group than those in the low TMB group.

\section{Overall survival (OS) and progression-free survival (PFS)}

In 11 studies involving 1688 NSCLC patients, we evaluated the relationship between TMB and PFS for ICI therapy. PFS for ICI therapy in the high TMB group was significantly better than that in the low TMB group (HR 0.81, 95\%CI 0.74-0.89, $p<0.00001$ ), and there was significant heterogeneity $\left(\mathrm{I}^{2}=53 \%, p=\right.$ 0.02) (Fig. 4A). Therefore, we performed a sensitivity analysis. After excluding the Goodman's study with the smallest weight $(1.1 \%)$ and the Rizvi's study with 
the largest weight $(15.7 \%)$, heterogeneity was unchanged and statistical result was stable. To further explore the sources of heterogeneity, we performed a subgroup analysis (Fig. 4B). In the Asian group, the PFS for ICI therapy of patients in the high TMB group was superior to that in the low TMB group (HR 0.69, $95 \% \mathrm{CI} 0.58-0.83, p<0.0001)$, while in the western group, there was no difference between the high TMB group and the low TMB group (HR 0.84, 95\% CI $0.76-0.92, p=0.0004)$. In the groups of anti-PD-1/ anti-PD-L1 therapy (HR 0.83, 95\%CI 0.75-0.92, $p=$ 0.0003 ) and anti-PD-1/anti-PD-L1 combined with anti-CTLA-4 therapy (HR 0.75, 95\%CI 0.62-0.90, $p=$ 0.002), the PFS for ICI therapy was superior for patients in the high TMB group than that in the low TMB group.

A

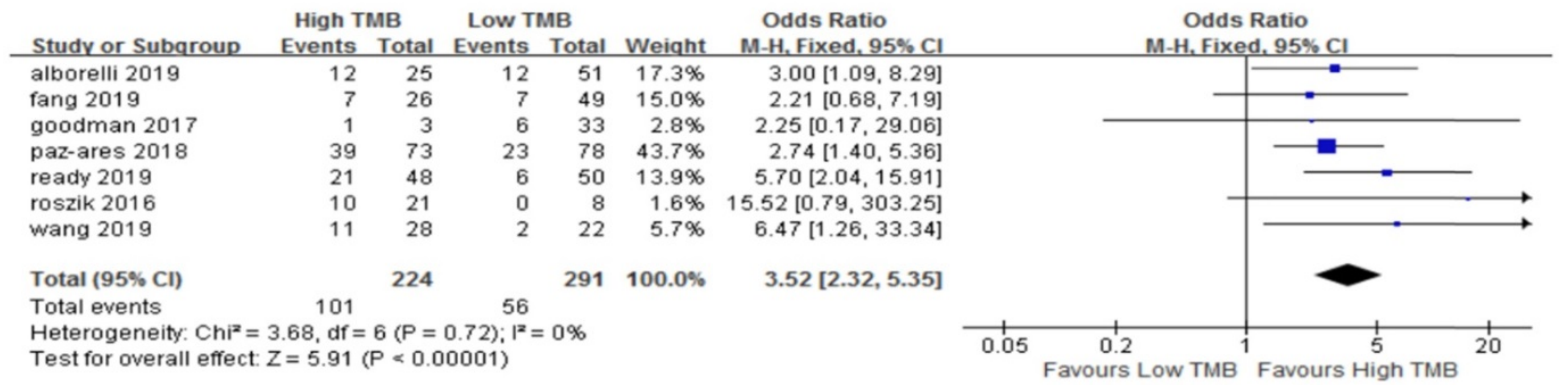

B

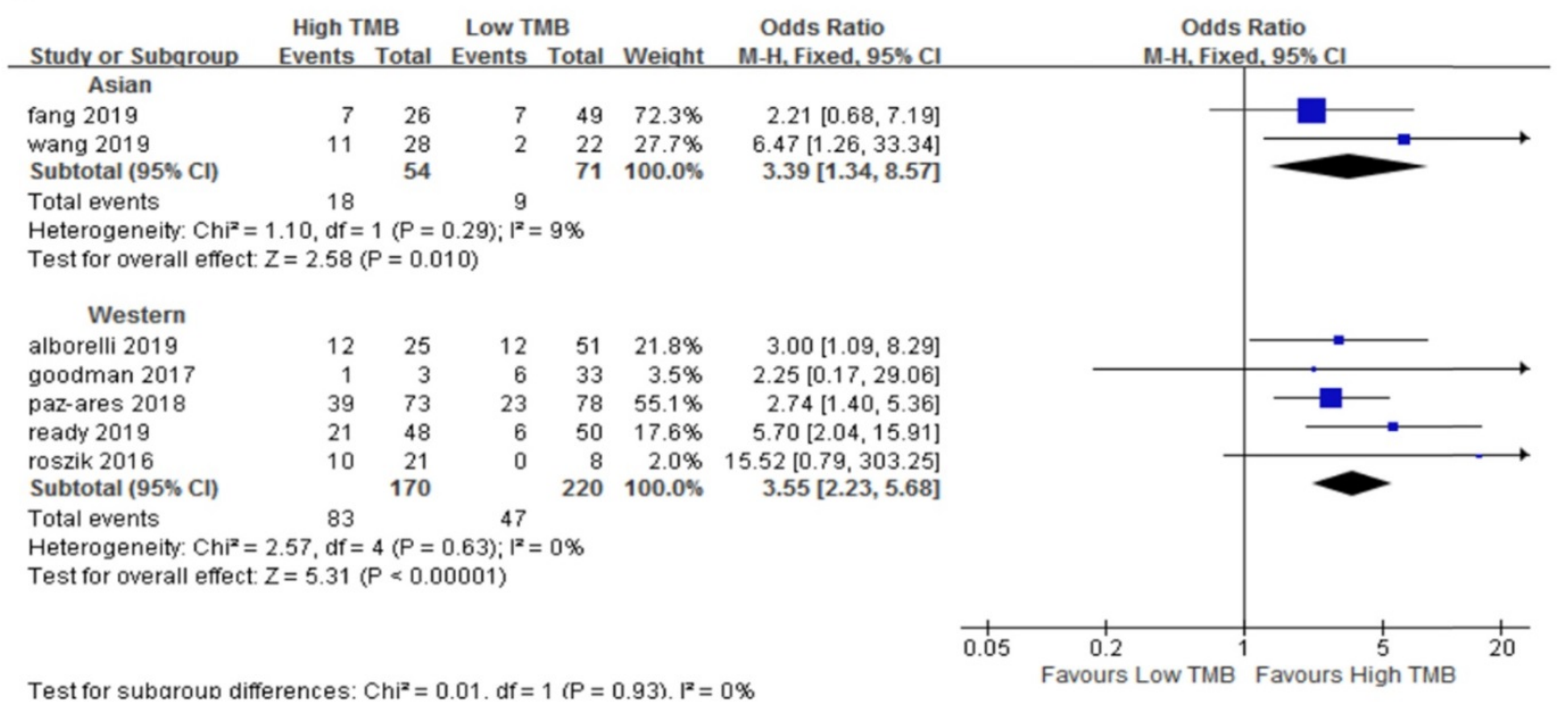

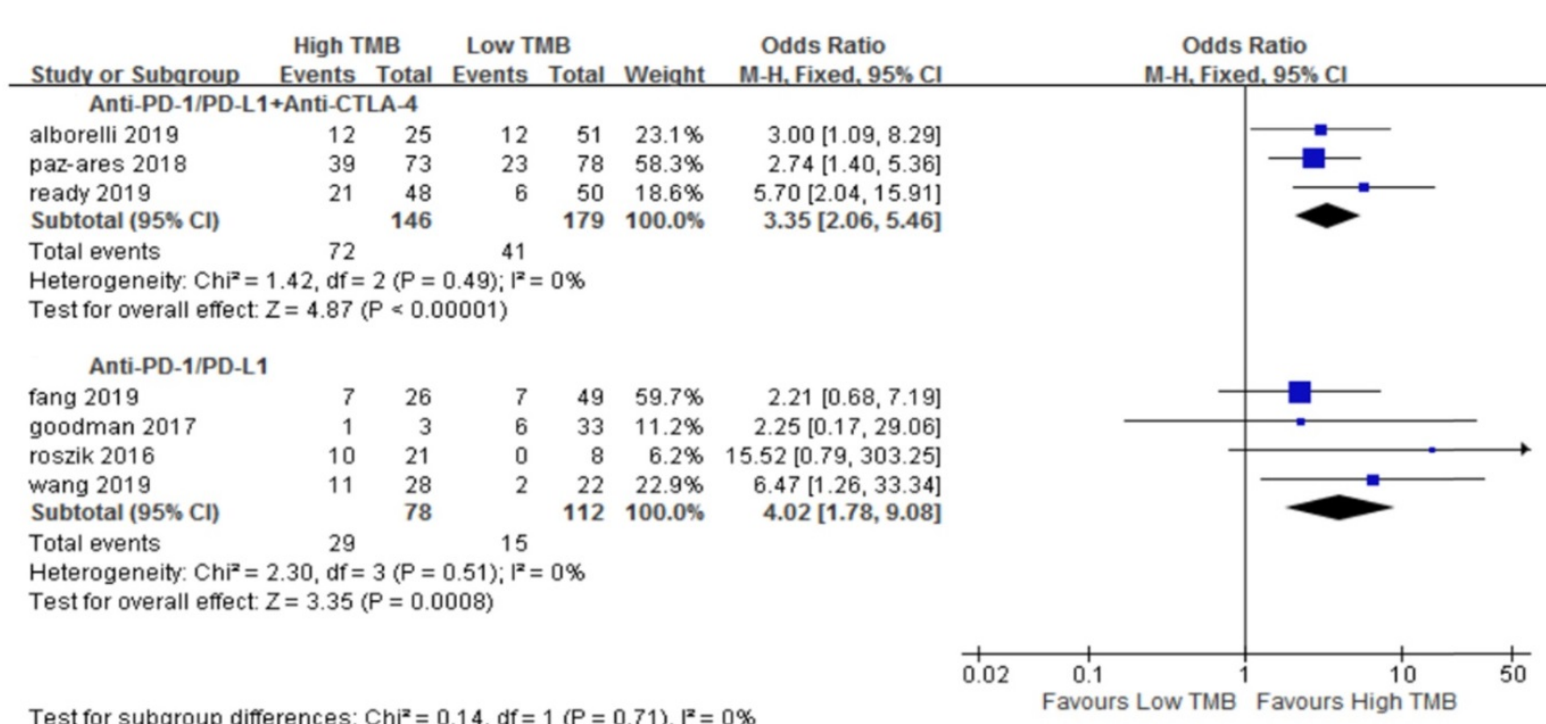

Figure 2. (A) Forest plot of association between TMB and ORR of immune checkpoint inhibitors. (B) Forest plot and pooled OR and $95 \% \mathrm{Cl}$ for subgroup ORR. TMB, tumor mutation burden; ORR, objective response rate; OR, odds ratio; $\mathrm{Cl}$, confidence interval. 
A

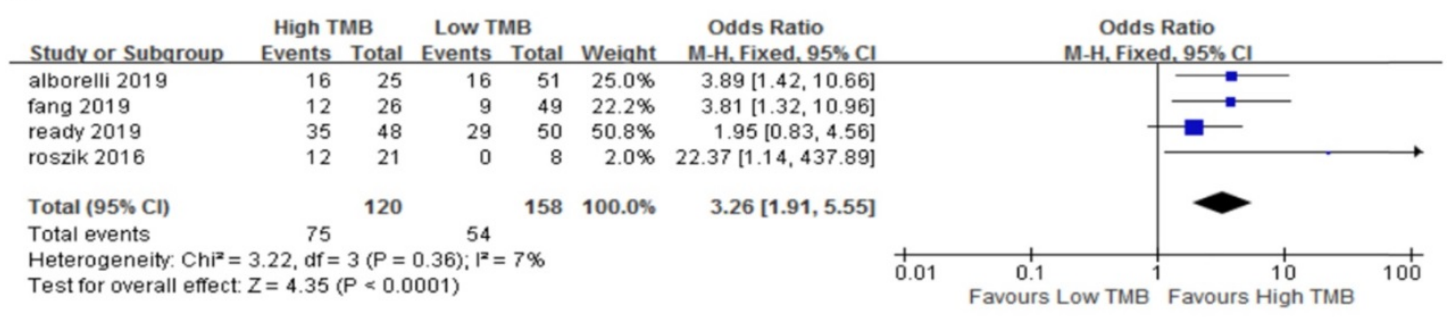

B

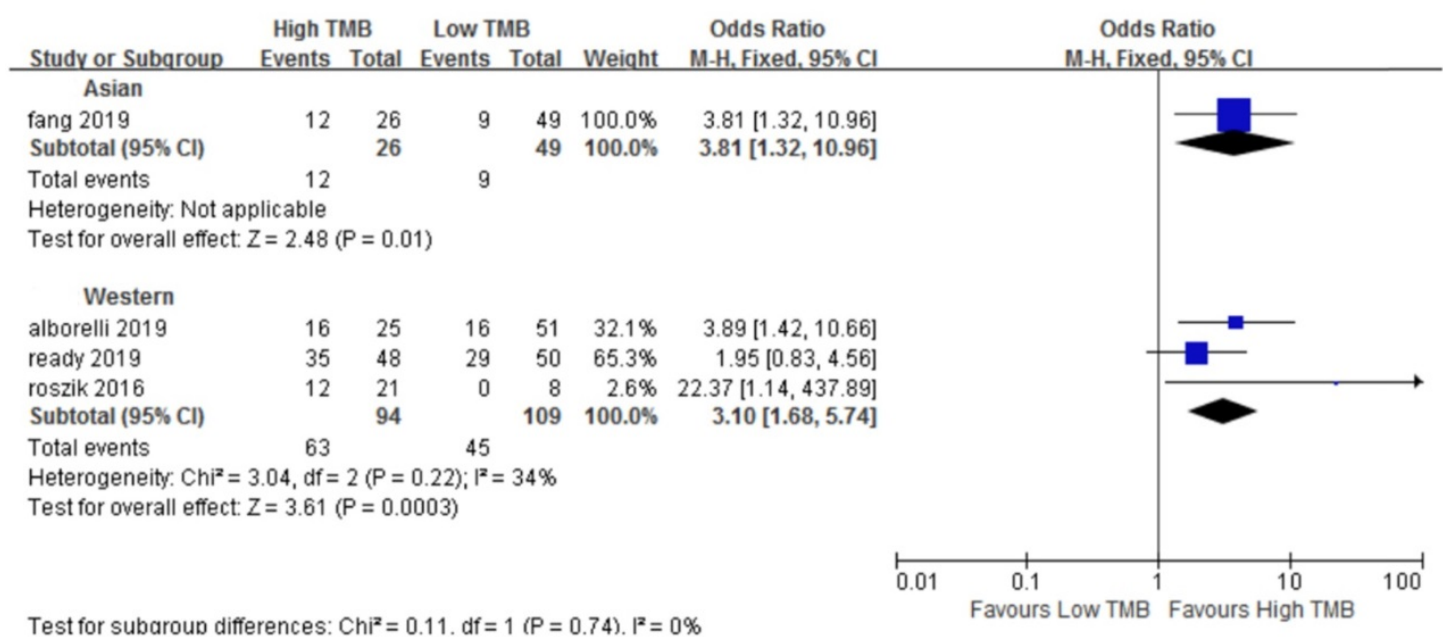

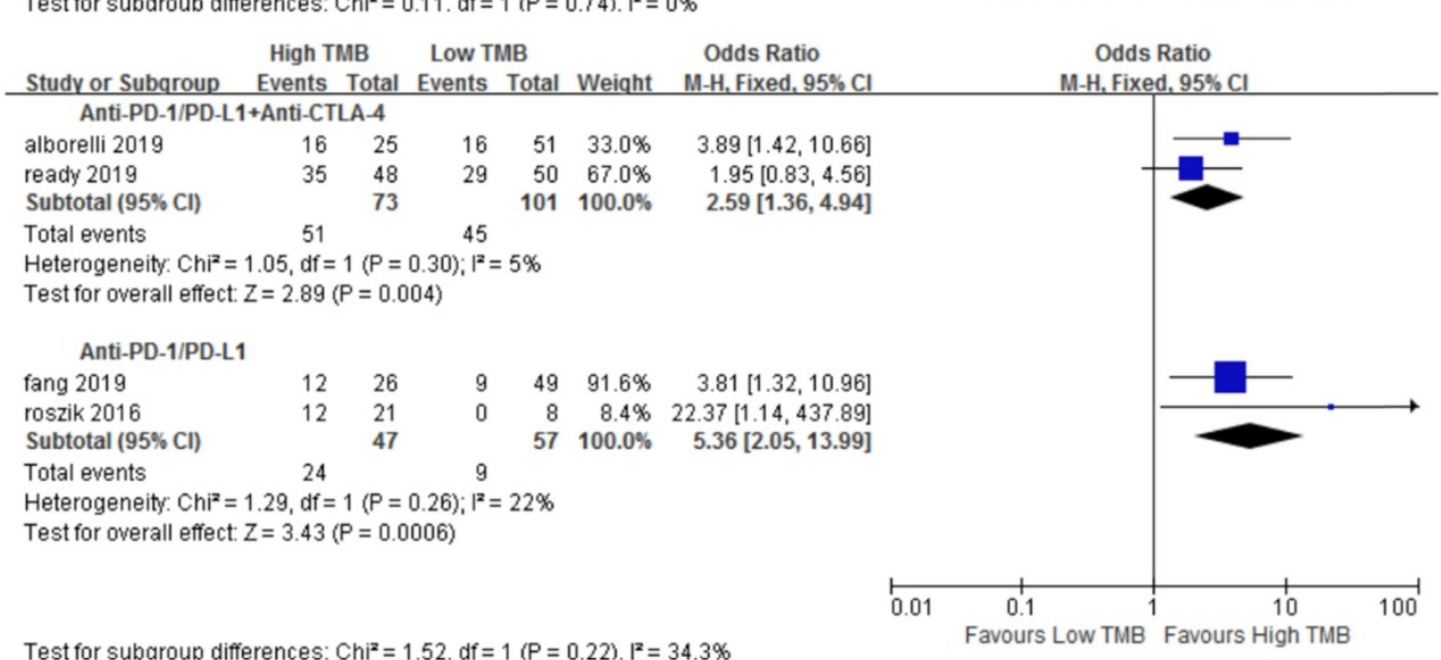

Figure 3. (A) Forest plot of association between TMB and DCR of immune checkpoint inhibitors. (B) Forest plot and pooled OR and $95 \%$ Cl for subgroup DCR. TMB, tumor mutation burden; DCR, disease control rate; OR, odds ratio; $\mathrm{Cl}$, confidence interval.

In 7 studies involving 2110 NSCLC patients, we evaluated the relationship between TMB and OS for ICI therapy. OS for ICI therapy in the high TMB group was significantly better than that in the low TMB group (HR 0.83, 95\% CI 0.74-0.94, $p=0.002$ ), and there was significant heterogeneity $\left(\mathrm{I}^{2}=52 \%, p=0.04\right)$ (Fig. $5 \mathrm{~A})$. We then performed a sensitivity analysis. After excluding the Reck's study with the largest weight $(24.4 \%)$ and Chae's study with the smallest weight $(1.3 \%)$, there was no significant change in the statistical result. To further explore the sources of heterogeneity, we performed a subgroup analysis
(Fig. 5B). In the anti-PD-1/anti-PD-L1 combined with anti-CTLA-4 therapy group, the OS for ICI therapy of patients in the high TMB group was superior to that in the low TMB group (HR 0.84, 95\%CI 0.71-1.00, $p=$ $0.04)$, while in the anti-PD-1/anti-PD-L1 therapy group, there was no difference between the high TMB group and the low TMB group (HR 0.83, 95\%CI $0.60-1.00, p=0.05)$.

\section{Publication bias}

After evaluation by Funnel plot, Egger's test and Begg's test, there was no evidence of publication bias $(p>0.05)$. 
A

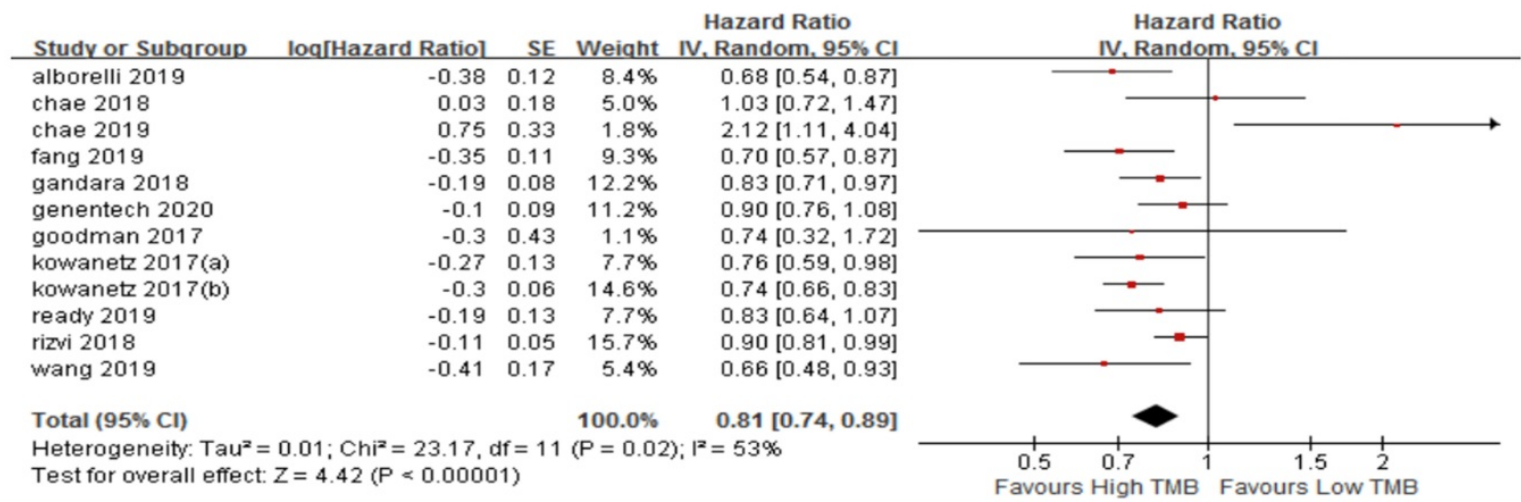

B

Hazard Ratio Hazard Ratio

\begin{tabular}{|c|c|c|c|c|}
\hline \multicolumn{2}{|c|}{ 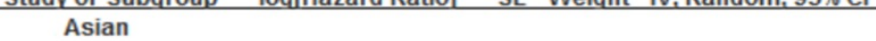 } & \multicolumn{3}{|c|}{ SE Weight IV, Random, $95 \% \mathrm{C}$} \\
\hline fang 2019 & -0.35 & 0.11 & $70.5 \%$ & $0.70[0.57,0.8$ \\
\hline wang 2019 & -0.41 & 0.17 & $29.5 \%$ & $0.66[0.48,0.9$ \\
\hline Subtotal $(95 \% \mathrm{Cl})$ & & & $100.0 \%$ & $0.69[0.58,0.8$ \\
\hline \multicolumn{5}{|c|}{$\begin{array}{l}\text { Heterogeneity: } \mathrm{Tau}^{2}=0.00 ; \mathrm{Chi}^{2}=0.09, \mathrm{df}=1(P=0.77) ; \mathrm{I}^{2}=0 \% \\
\text { Test for overall effect: } Z=3.98(P<0.0001)\end{array}$} \\
\hline \multicolumn{5}{|l|}{ Western } \\
\hline alborelli 2019 & -0.38 & 0.12 & $9.8 \%$ & $0.68[0.54,0.8$ \\
\hline chae 2018 & 0.03 & 0.18 & $5.8 \%$ & $1.03[0.72,1.4$ \\
\hline chae 2019 & 0.75 & 0.33 & $2.1 \%$ & $2.12[1.11,4$. \\
\hline gandara 2018 & -0.19 & 0.08 & $14.4 \%$ & $0.83[0.71,0.9$ \\
\hline genentech 2020 & -0.1 & 0.09 & $13.1 \%$ & $0.90[0.76,1.0$ \\
\hline goodman 2017 & -0.3 & 0.43 & $1.3 \%$ & $0.74[0.32,1]$. \\
\hline kowanetz 2017 (a) & -0.27 & 0.13 & $9.0 \%$ & $0.76[0.59,0$. \\
\hline kowanetz 2017(b) & -0.3 & 0.06 & $17.1 \%$ & $0.74[0.66,0.8]$ \\
\hline ready 2019 & -0.19 & 0.13 & $9.0 \%$ & $0.83[0.64,1.0$ \\
\hline rizvi 2018 & -0.11 & 0.05 & $18.5 \%$ & $0.90[0.81,0$ \\
\hline Subtotal $(95 \% \mathrm{Cl})$ & & & $100.0 \%$ & $0.84[0.76,0$. \\
\hline
\end{tabular}

Heterogeneity: $\mathrm{Tau}^{2}=0.01 ; \mathrm{Chi}^{2}=19.40, \mathrm{df}=9(\mathrm{P}=0.02) ; \mathrm{I}^{2}=54 \%$

Test for overall effect: $Z=3.55(P=0.0004)$

Test for subaroun differences: $C h i^{2}=3.29 . d f=1(P=0.07) . I^{2}=69.6 \%$

Odds Ratio

\begin{tabular}{|c|c|c|c|c|}
\hline Study or Subqroup & log[Odds Ratiol & SE & Weight & IV. Random, $95 \% \mathrm{Cl}$ \\
\hline \multicolumn{5}{|c|}{ Anti-PD-1/PD-L1 } \\
\hline chae 2018 & 0.03 & 0.18 & $6.1 \%$ & $1.03[0.72,1.47]$ \\
\hline chae 2019 & 0.75 & 0.33 & $2.3 \%$ & $2.12[1.11,4.04]$ \\
\hline fang 2019 & -0.35 & 0.11 & $11.2 \%$ & $0.70[0.57,0.87]$ \\
\hline gandara 2018 & -0.19 & 0.08 & $14.5 \%$ & $0.83[0.71,0.97]$ \\
\hline genentech 2020 & -0.1 & 0.09 & $13.3 \%$ & $0.90[0.76,1.08]$ \\
\hline goodman 2017 & -0.3 & 0.43 & $1.4 \%$ & $0.74[0.32,1.72]$ \\
\hline kowanetz 2017 (a) & -0.27 & 0.13 & $9.3 \%$ & $0.76[0.59,0.98]$ \\
\hline kowanetz 2017(b) & -0.3 & 0.06 & $17.0 \%$ & $0.74[0.66,0.83]$ \\
\hline rizvi 2018 & -0.11 & 0.05 & $18.3 \%$ & $0.90[0.81,0.99]$ \\
\hline wang 2019 & -0.41 & 0.17 & $6.6 \%$ & $0.66[0.48,0.93]$ \\
\hline Subtotal $(95 \% \mathrm{CI})$ & & & $100.0 \%$ & $0.83[0.75,0.92]$ \\
\hline \multicolumn{5}{|c|}{$\begin{array}{l}\text { Heterogeneity: } \text { Tau }^{2}=0.01 ; \mathrm{Chi}^{2}=20.76, \mathrm{df}=9(P=0.01) ; \mathrm{I}^{2}=57 \% \\
\text { Test for overall effect: } Z=3.60(P=0.0003)\end{array}$} \\
\hline \multicolumn{5}{|c|}{ Anti-PD-1/PD-L1+Anti-CTLA4 } \\
\hline alborelli 2019 & -0.38 & 0.12 & $53.5 \%$ & $0.68[0.54,0.87]$ \\
\hline ready 2019 & -0.19 & 0.13 & $46.5 \%$ & $0.83[0.64,1.07]$ \\
\hline Subtotal $(95 \% \mathrm{CI})$ & & & $100.0 \%$ & $0.75[0.62,0.90]$ \\
\hline \multicolumn{5}{|c|}{$\begin{array}{l}\text { Heterogeneity: } \operatorname{Tau}^{2}=0.00 ; \mathrm{Chi}^{2}=1.15, \mathrm{df}=1(P=0.28) ; \mathrm{I}^{2}=13 \% \\
\text { Test for overall effect: } Z=3.08(P=0.002)\end{array}$} \\
\hline
\end{tabular}

Test for subaroun differences: $\mathrm{Chi}^{2}=0.90 . \mathrm{df}=1(\mathrm{P}=0.34) . \mathrm{I}^{\mathrm{2}}=0 \%$

IV, Random, $95 \% \mathrm{Cl}$

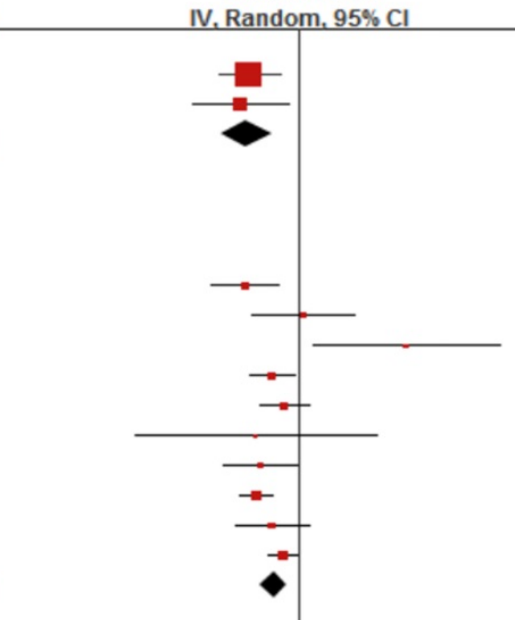

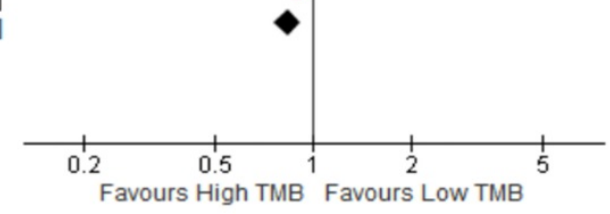

Favours High TMB Favours Low TMB

Odds Ratio IV. Random, $95 \% \mathrm{Cl}$

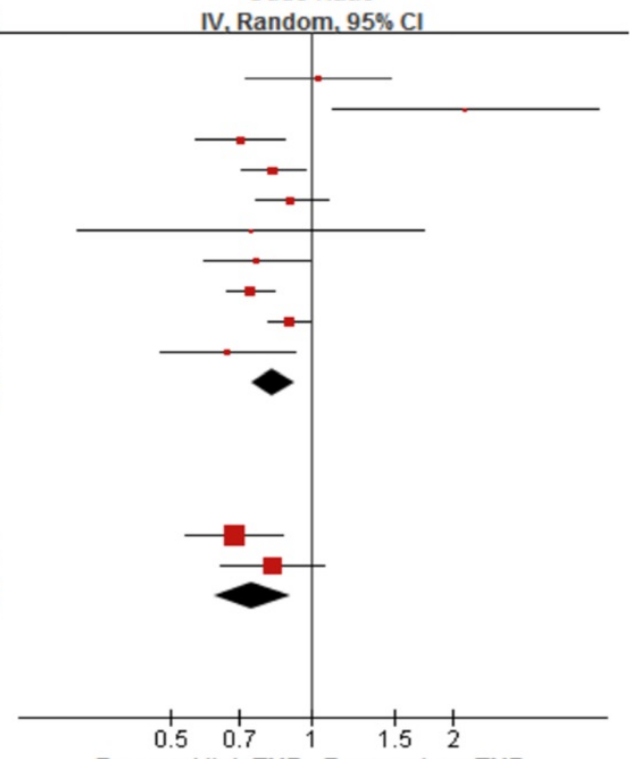

Favours High TMB Favours Low TMB

Figure 4. (A) Forest plot of association between TMB and PFS of immune checkpoint inhibitors. (B) Forest plot and pooled HR and $95 \%$ Cl for subgroup PFS. TMB, tumor mutation burden; PFS, progression-free survival; $\mathrm{HR}$, hazard ratio; $\mathrm{Cl}$, confidence interval. 
A

\begin{tabular}{|c|c|c|c|c|c|c|}
\hline Study or Subqroup & log[Hazard Ratio] & SE & Weight & $\begin{array}{c}\text { Hazard Ratio } \\
\text { IV. Random, } 95 \% \mathrm{Cl}\end{array}$ & $\begin{array}{r}\text { Hazard } \\
\text { IV, Randor }\end{array}$ & $\begin{array}{l}\text { d Ratio } \\
\text { om, 95\% Cl }\end{array}$ \\
\hline alborelli 2019 & -0.29 & 0.11 & $14.6 \%$ & $0.75[0.60,0.93]$ & & \\
\hline chae 2018 & -1 & 0.5 & $1.3 \%$ & $0.37[0.14,0.98]$ & 4 & \\
\hline chae 2019 & 0.78 & 0.34 & $2.8 \%$ & $2.18[1.12,4.25]$ & & \\
\hline gandara 2018 & -0.19 & 0.08 & $19.2 \%$ & $0.83[0.71,0.97]$ & $\rightarrow-$ & \\
\hline goodman 2017 & -0.28 & 0.13 & $12.2 \%$ & $0.76[0.59,0.98]$ & & \\
\hline kowanetz 2017(a) & -0.35 & 0.21 & $6.3 \%$ & $0.70[0.47,1.06]$ & & \\
\hline kowanetz $2017(b)$ & -0.15 & 0.08 & $19.2 \%$ & $0.86[0.74,1.01]$ & $\rightarrow$ & \\
\hline reck 2019 & -0.11 & 0.05 & $24.4 \%$ & $0.90[0.81,0.99]$ & $\rightarrow$ & \\
\hline Total $(95 \% \mathrm{Cl})$ & & & $100.0 \%$ & $0.83[0.74,0.94]$ & & \\
\hline \multicolumn{5}{|c|}{$\begin{array}{l}\text { Heterogeneity: } \text { Tau }^{2}=0.01 ; \mathrm{Chi}^{2}=14.69, \mathrm{df}=7(P=0.04) ; \mathrm{I}^{2}=52 \% \\
\text { Test for overall effect: } Z=3.08(P=0.002)\end{array}$} & $\begin{array}{cc}0.5 & 0.7 \\
\text { Favours High TMB }\end{array}$ & $1 \frac{1.5}{\text { Favours LC }}$ \\
\hline
\end{tabular}

B

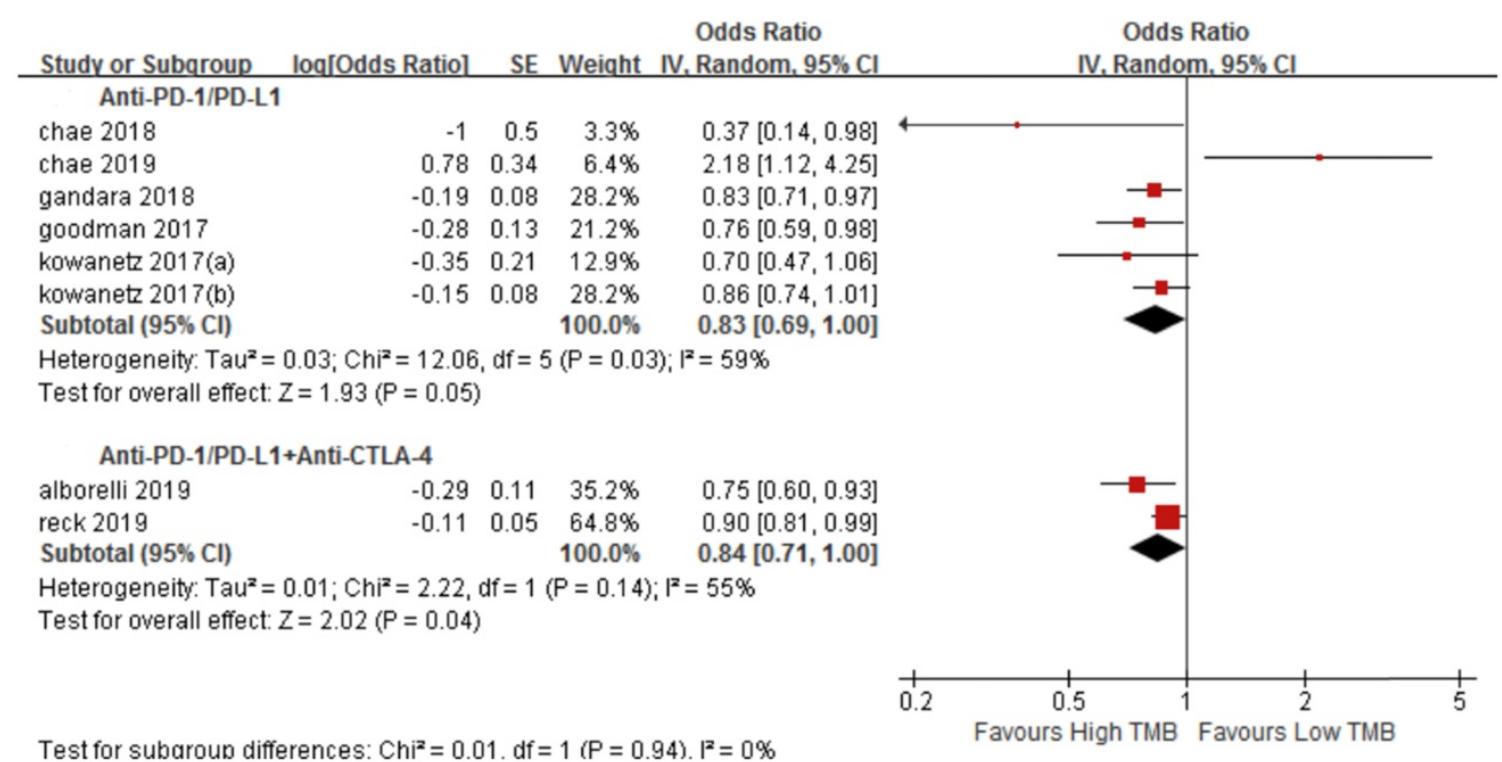

Figure 5. (A) Forest plot of association between TMB and OS of immune checkpoint inhibitors. (B) Forest plot and pooled HR and $95 \% \mathrm{Cl}$ for subgroup OS. TMB, tumor mutation burden; OS, overall survival; $\mathrm{HR}$, hazard ratio; $\mathrm{Cl}$, confidence interval.

\section{Evidence level}

According to the GRADE grading method, we analyzed the evidence level of each result, and the results showed that the evidence level of ORR and DCR was very high. For survival time, the evidence level of PFS and OS was moderate (Fig. 6).

\section{Discussion}

Lung cancer is still the most common cause of cancer death worldwide, killing more than a million people each year [27]. Most NSCLC patients are advanced at the time of diagnosis. In recent years, immunotherapy has been gradually applied to the therapy of NSCLC, and the selection of appropriate patients for immunotherapy is the focus of current therapy, and the selection of suitable patients with appropriate predictive indicators is the most important.

In previous studies, TMB was determined by whole exome sequencing (WES). WES can provide a comprehensive overview of protein-coding gene changes, but its high cost and time-consuming lead to limitations in routine practice $[28,29]$. Although WES is still the standard method for quantifying $\mathrm{TMB}$, there is growing evidence that targeted NGS panels with greater clinical value can also be used for sequencing TMB if sufficient genomic regions are covered [30]. The US Food and Drug Administration (FDA) have approved Foundation One CDx and MSK-IMPACT for general clinical gene analysis. Although it has not yet been approved for these specific uses, most oncology platforms currently use targeted NGS for TMB sequencing [4,31].We included all studies that used targeted NGS as a TMB sequencing method and performed a meta-analysis.

First, we used ORR and DCR as the endpoints of our analysis to assess the effectiveness of ICI therapy. Hellman [32] howed that the ORR of NSCLC patients in the high TMB group for ICI therapy was superior to 
that in the low TMB group ( $p=0.0005)$, ORR increased by $48 \%$. Goodman [23] showed that the ORR of NSCLC patients in the high TMB group treated with ICI was superior to that in the low TMB group $(p=$ $0.0077)$, ORR increased by $15 \%$. Rizvi [12] showed that DCR of NSCLC patients treated with ICI in the high TMB group was superior to that in the low TMB group $(p=0.0011)$, DCR increased by $47 \%$. We evaluated the relationship between TMB and the ORR and DCR of ICI therapy respectively. The results of meta-analysis were similar to the above results, indicating that the ORR and DCR of ICI therapy in the high TMB group were higher than those in the low TMB group, and there was no heterogeneity. In order to screen the predominant population for ICI therapy, we further performed a subgroup analysis. We performed group evaluations from the patient region and immunotherapy protocol. We found no matter regions (Asian and western people) or the immunotherapy protocols (anti-PD-1/PD-L1 combined with anti-CTLA 4 therapy and anti-PD-1/PD-L1 monotherapy), the ORR and DCR of ICI therapy in the high TMB groups were both higher than those in the low TMB groups. This suggests that we can screen patients for ICI therapy according to the level of TMB, which may have some significance for the advanced therapy of NSCLC.

In recent years, many studies have confirmed that ICI therapy can prolong PFS and OS in NSCLC patients $[33,34,35]$, but some studies still hold the opposite view $[15,20]$. In order to further screen suitable NSCLC patients for ICI therapy, we used the TMB threshold to judge the predictive ability of survival time of ICI therapy. Hellman [32] used WES method, and showed that the median PFS of high TMB group and low TMB group treated with ICI was 17.1 months versus 3.7 months $(p=0.0024)$, Alborelli [16] showed that the median PFS of high TMB group and low TMB group treated with ICI was 16.4 months versus 2.6 months $(p=0.0014)$, the median OS was 37.5 months versus 9 months $(p=0.0197)$, and Fang [22] showed that the median PFS of the high and low TMB groups treated with ICI was 4.3 months versus 2.0 months $(p=0.0018)$. However, Chae [20] showed that the PFS and OS of ICI therapy in low TMB group were both better than those in high TMB group. The results of this meta-analysis showed that patients with high TMB had superior PFS and OS in ICI therapy than those in low TMB, but the heterogeneity was obvious. Sensitivity analysis indicated stable results. In order to explore the source of heterogeneity and screen the dominant population, we further performed subgroup analysis. First, most of the studies included in this meta-analysis were conducted in western populations, and the meta-analysis results showed no significant difference between the PFS of ICI therapy in the high TMB group and the low TMB group. The analysis of Asian people showed that the PFS of ICI therapy in the high TMB group was better than that in the low TMB group, which may suggest

\begin{tabular}{|c|c|c|c|c|c|c|c|c|c|c|c|c|}
\hline \multicolumn{7}{|c|}{ Certainty assessment } & \multicolumn{2}{|c|}{ No of patients } & \multicolumn{2}{|c|}{ Effect } & \multirow[b]{2}{*}{ Certainty } & \multirow[b]{2}{*}{ Importance } \\
\hline $\begin{array}{c}\text { No of } \\
\text { studies }\end{array}$ & $\begin{array}{l}\text { Study } \\
\text { design }\end{array}$ & $\begin{array}{c}\text { Risk of } \\
\text { bias }\end{array}$ & $\begin{array}{c}\text { Inconsis- } \\
\text { tency }\end{array}$ & $\begin{array}{c}\text { Indirect- } \\
\text { ness }\end{array}$ & $\begin{array}{c}\text { Impreci- } \\
\text { sion }\end{array}$ & $\begin{array}{c}\text { Other } \\
\text { considerations }\end{array}$ & $\begin{array}{l}\text { High } \\
\text { TMBB }\end{array}$ & $\begin{array}{l}\text { Low } \\
\text { TMB }\end{array}$ & $\begin{array}{c}\text { Relative } \\
(95 \% \text { CI) }\end{array}$ & $\begin{array}{l}\text { Absolute } \\
\text { (95\% CI) }\end{array}$ & & \\
\hline \multicolumn{13}{|l|}{ ORR } \\
\hline 7 & $\begin{array}{l}\text { observa- } \\
\text { tional } \\
\text { studies }\end{array}$ & $\begin{array}{c}\text { not } \\
\text { serious }\end{array}$ & $\begin{array}{c}\text { not } \\
\text { serious }\end{array}$ & $\begin{array}{c}\text { not } \\
\text { serious }\end{array}$ & $\begin{array}{c}\text { not } \\
\text { serious }\end{array}$ & $\begin{array}{l}\text { very strong } \\
\text { association } \\
\text { dose response } \\
\text { gradient }\end{array}$ & $\begin{array}{l}101 / 224 \\
(45.1 \%)\end{array}$ & $\begin{array}{c}56 / 291 \\
(19.2 \%)\end{array}$ & $\begin{array}{l}\text { OR 3.52 } \\
\text { (2.32 to } \\
5.35)\end{array}$ & $\begin{array}{c}0 \text { fewer per } \\
1,000 \\
\text { (from } 0 \text { fewer } \\
\text { to } 0 \text { fewer) }\end{array}$ & $\begin{array}{c}\oplus \oplus \oplus \oplus \\
\text { HIGH }\end{array}$ & IMPORTANT \\
\hline \multicolumn{13}{|l|}{ DCR } \\
\hline 4 & $\begin{array}{l}\text { observa- } \\
\text { tional } \\
\text { studies }\end{array}$ & $\begin{array}{c}\text { not } \\
\text { serious }\end{array}$ & $\begin{array}{c}\text { not } \\
\text { serious }\end{array}$ & $\begin{array}{c}\text { not } \\
\text { serious }\end{array}$ & $\begin{array}{c}\text { not } \\
\text { serious }\end{array}$ & $\begin{array}{l}\text { very strong } \\
\text { association } \\
\text { dose response } \\
\text { gradient }\end{array}$ & $\begin{array}{l}75 / 120 \\
(62.5 \%)\end{array}$ & $\begin{array}{c}54 / 158 \\
(34.2 \%)\end{array}$ & $\begin{array}{c}\text { OR 3.26 } \\
\text { (1.91 to } \\
5.55)\end{array}$ & $\begin{array}{l}0 \text { fewer per } \\
\quad 1,000 \\
\text { (from } 0 \text { fewer } \\
\text { to } 0 \text { fewer) }\end{array}$ & $\begin{array}{c}\oplus \oplus \oplus \oplus \\
\text { HIGH }\end{array}$ & IMPORTANT \\
\hline \multicolumn{13}{|l|}{ PFS } \\
\hline 12 & $\begin{array}{l}\text { observa- } \\
\text { tional } \\
\text { studies }\end{array}$ & $\begin{array}{c}\text { not } \\
\text { serious }\end{array}$ & serious & $\begin{array}{c}\text { not } \\
\text { serious }\end{array}$ & $\begin{array}{c}\text { not } \\
\text { serious }\end{array}$ & $\begin{array}{c}\text { strong } \\
\text { association } \\
\text { dose response } \\
\text { gradient }\end{array}$ & $-/ 0$ & $-/ 0$ & $\begin{array}{c}\text { HR } 0.81 \\
(0.74 \text { to } \\
0.89)\end{array}$ & $\begin{array}{c}1 \text { fewer per } \\
\mathbf{1 , 0 0 0} \\
\text { (from } 1 \text { fewer } \\
\text { to } 1 \text { fewer) }\end{array}$ & $\begin{array}{c}\oplus \oplus \oplus \bigcirc \\
\text { MODERATE }\end{array}$ & IMPORTANT \\
\hline \multicolumn{13}{|l|}{ os } \\
\hline 8 & $\begin{array}{l}\text { observa- } \\
\text { tional } \\
\text { studies }\end{array}$ & $\begin{array}{c}\text { not } \\
\text { serious }\end{array}$ & serious & $\begin{array}{c}\text { not } \\
\text { serious }\end{array}$ & $\begin{array}{c}\text { not } \\
\text { serious }\end{array}$ & $\begin{array}{c}\text { strong } \\
\text { association } \\
\text { dose response } \\
\text { gradient }\end{array}$ & $-/ 0$ & $-/ 0$ & $\begin{array}{c}\text { HR } 0.85 \\
(0.74 \text { to } \\
0.94)\end{array}$ & $\begin{array}{c}1 \text { fewer per } \\
\mathbf{1 , 0 0 0} \\
\text { (from } 1 \text { fewer } \\
\text { to } 1 \text { fewer) }\end{array}$ & $\begin{array}{c}\oplus \oplus \oplus \bigcirc \\
\text { VERY LOW }\end{array}$ & IMPORTANT \\
\hline
\end{tabular}


that the TMB threshold may be suitable to screen the superior group of ICI therapy in the Asian people. In addition, we found that in the subgroup analysis of PFS, among the anti-PD-1/PD-L1 monotherapy group $(p=0.04)$ and anti-PD-1/PD-L1 combined with anti-CTLA-4 therapy group $(p=0.04)$, the PFS of ICI therapy in the high TMB group was superior to low TMB group. In the subgroup analysis of OS, OS of ICI therapy in patients with high TMB was superior to patients with low TMB in anti-PD-1/PD-L1 combined with anti-CTLA-4 therapy group $(p=0.04)$; and there was no difference in OS between the patients with high TMB and low TMB in anti-PD-1 / PD-L1 therapy group $(p=0.45)$. At present, there have been a lot of reports on anti-CTLA-4, anti-PD-1 and anti-PD-L1. Studies [36] have shown that in the tumor microenvironment, anti-CTLA-4 stimulates the activation of surrounding $\mathrm{T}$ cells by blocking the binding of CTLA- 4 on the surface of T cells to the ligand CD80/ CD86 on APCs, but does not activate $\mathrm{T}$ cells. Anti-PD-1/PD-L1 may play an anti-tumor effect by activating $\mathrm{T}$ lymphocytes. Although both are negative signals for $\mathrm{T}$ cell activation, their location and timing are different. CTLA-4 is expressed on T cells, while PD-1 is more widely expressed on a variety of cells. Normally, CTLA-4 suppresses $\mathrm{T}$ cells in the early stages of the immune cycle in lymph nodes, while PD-1 regulates the immune response in peripheral tissues or tumor sites [37,38]. Pardoll's study demonstrated that anti-PD-1 targeting tumor infiltrating lymphocytes (TIL) can complement the anti-tumor activity of anti-CTLA-4 through nonredundant pathways [39].

In order to further verify our conclusion, we searched for an open access data platform-MSKCC through http://www.cbioportal.org. The database included 1662 patients with advanced cancer who were treated with ICI, of which 350 patients were diagnosed with NSCLC [40]. We further obtained the TMB threshold histogram (sFigure 1) and survival curve (sFigure 2) of 350 patients. The results showed that patients with $\mathrm{TMB}$ threshold $\geq 12.27$ have significantly better OS than patients with TMB threshold <12.27, which is consistent with our conclusion similar.

Finally, we analyzed the quality of the included studies and the level of evidence for outcome indicators discussed. NOS table indicated the relatively high quality of the included studies and improves the reliability of the meta-analysis. GRADE classification indicated the level of evidence for ORR and DCR was high, so it is reasonable to expect that the true effect is close to the estimated effect. For PFS and OS, we have limited confidence in the effect estimates and need to further enrich the included studies.

This meta-analysis is limited by several aspects. First of all, the sample sizes of the included studies are different, leading to large differences in sample sizes among different subgroups. Among them, the smaller the sample size, the more studies may be the main source of affecting the quality of the meta-analysis. Secondly, although the studies we included all adopted targeted NGS, the specific sequencing panel was different, which resulted in a certain fluctuation range of the TMB cut-off value and also affected the quality of meta-analysis to a certain extent. In addition, we lack data on comorbidities, ECOG scores, and previous treatment regimens for patients, which may play an important role in the effectiveness of ICI.

\section{Conclusions}

TMB is a promising biomarker, which can predict the efficacy of ICI therapy in advanced NSCLC patients, included ORR, DCR, PFS and OS. Therefore, the advance measurement of TMB in clinical diagnosis can provide a basis for the treatment of patients with advanced NSCLC.

\section{Supplementary Material}

Supplementary figures.

http://www.jcancer.org/v12p0584s1.pdf

\section{Acknowledgements}

The material is original research, has not been previously published and has not been submitted for publication elsewhere while under consideration.

\section{Funding}

This work was supported by National Natural Science Foundation of China (Grant No. 81774221), The Capital Health Research and Development of Special (No. 2018-2-1113), Basic-Clinical Cooperation Program from Capital Medical University (No. 17JL14), Research Foundation of Beijing Friendship Hospital, Capital Medical University (No. yyqdkt2016-4), and the Beijing Municipal 215 Highlevel Health Person Foundation Project (No. 2014-3004).

\section{Authors' contributions}

Xiaoting Ma: Wrote the manuscript, collected materials, and consulted the literature; Yujian Zhang: Contributed to the conception, designed this study; Shan Wang: Contributed to the conception, designed this study; Jing Yu: Revised the paper and provided funding. 


\section{Competing Interests}

The authors have declared that no competing interest exists.

\section{References}

1. Chen $\mathrm{Q}, \mathrm{Li}$ T, Yue W. Drug response to PD-1/PD-L1 blockade: based on biomarkers. Onco Targets Ther. 2018; 11: 4673-4683.

2. Havel JJ, Chowell D, Chan TA. The evolving landscape of biomarkers for checkpoint inhibitor immunotherapy. Nat Rev Cancer. 2019; 19: 133-150.

3. Yi M, Jiao D, Xu H, et al. Biomarkers for predicting efficacy of PD-1/PD-L1 inhibitors. Mol Cancer. 2018; 17:129.

4. Duffy MJ, Crown J. Biomarkers for Predicting Response to Immunotherapy with Immune Checkpoint Inhibitors in Cancer Patients. Clin Chem. 2019; 65(10): 1228-1238.

5. Galuppini F, Dal Pozzo CA, Deckert J, et al. Tumor mutation burden: from comprehensive mutational screening to the clinic. Cancer Cell Int. 2019; 19: 209.

6. Gubin MM, Artyomov MN, Mardis ER, et al. Tumor neoantigens: building a framework for personalized cancer immunotherapy. J Clin Invest 2015; 125: 3413-3421.

7. Gandara DR, Paul SM, Kowanetz M, et al. Blood-based tumor mutational burden as a predictor of clinical benefifit in non-small-cell lung cancer patients treated with atezolizumab. Nat Med. 2018; 24: 1441-1448.

8. Bu“ttner R, Longshore JW, Lo'pez-R1'os F, et al. Implementing TMB measurement in clinical practice: considerations on assay requirements. ESMO Open. 2019; 4(1):e 000442

9. Samstein RM, Lee CH, Shoushtari AN, et al. Tumor mutational load predicts survival after immunotherapy across multiple cancer types. Nat Genet. 2019; 51: 202-206.

10. Hellmann MD, Callahan MK, Awad MM, et al. Tumor mutational burden and efficacy of nivolumab monotherapy and in combination with ipilimumab in small-cell lung cancer. Cancer Cell. 2018; 33: 853-861.

11. Berland L, Heeke S, Humbert $\mathrm{O}$, et al. Current views on tumor mutational burden in patients with non-small cell lung cancer treated by immune checkpoint inhibitors. J Thorac Dis. 2019; 11(Suppl 1): S71-S80.

12. Rizvi NA, Hellmann MD, Snyder A, et al. Cancer immunology. Mutational landscape determines sensitivity to PD-1 blockade in non-small cell lung cancer. Science. 2015; 348: 124-128.

13. Klempner SJ, Fabrizio D, Bane S, et al. Tumor Mutational Burden as a Predictive Biomarker for Response to Immune Checkpoint Inhibitors: A Review of Current Evidence. Oncologist. 2020; 25(1): e147-e159.

14. Rizvi H, Sanchez-Vega F, La K, et al. Molecular Determinants of Response to Anti-Programmed Cell Death (PD)-1 and Anti-Programmed Death-Ligand 1 (PD-L1) Blockade in Patients With Non-Small-Cell Lung Cancer Profiled With Targeted Next-Generation Sequencing. J Clin Oncol. 2018; 36(7): 633-641.

15. Chae YK, Davis AA, Raparia K, et al. Association of Tumor Mutational Burden With DNA Repair Mutations and Response to Anti-PD-1/PD-L1 Therapy in Non-Small-Cell Lung Cancer. Clin Lung Cancer. 2019; 20(2): 88-96.e6.

16. Alborelli I, Leonards K, Rothschild SI, et al. Tumor mutational burden assessed by targeted NGS predicts clinical benefit from immune checkpoint inhibitors in non-small cell lung cancer. J Pathol. 2020; 250(1): 19-29.

17. Ready N, Hellmann MD, Awad MM, et al. First-Line Nivolumab Plus Ipilimumab in Advanced Non-Small-Cell Lung Cancer (CheckMate 568): Outcomes by Programmed Death Ligand 1 and Tumor Mutational Burden as Biomarkers. J Clin Oncol. 2019; 37(12): 992-1000.

18. Paz-Ares, L. Urban, C. Audigier-Valette, et al. CheckMate 817: Safety of FlatDose Nivolumab Plus Weight-Based Ipilimumab for the First-line (1L) Treatment of Advanced NSCLC. Journal of Thoracic Oncology. 2018; 13(10): S493.

19. Wang Z, Duan J, Cai S, et al. Assessment of Blood Tumor Mutational Burden as a Potential Biomarker for Immunotherapy in Patients With Non-Small Cell Lung Cancer With Use of a Next-Generation Sequencing Cancer Gene Panel. JAMA Oncol. 2019; 5(5): 696-702.

20. Chae YK, Davis AA, Agte S. Clinical Implications of Circulating Tumor DNA Tumor Mutational Burden (ctDNA TMB) in Non-Small Cell Lung Cancer. Oncologist. 2019; 24(6): 820-828

21. Reck M, Schenker $\mathrm{M}$, Lee $\mathrm{KH}$, et al. Nivolumab plus ipilimumab versus chemotherapy as first-line treatment in advanced non-small-cell lung cancer with high tumour mutational burden: patient-reported outcomes results from the randomised, open-label, phase III CheckMate 227 trial. Eur J Cancer. 2019; 116: 137-147.

22. Fang W, Ma Y, Yin JC, et al. Comprehensive Genomic Profiling Identifies Novel Genetic Predictors of Response to Anti-PD-(L)1 Therapies in Non-Small Cell Lung Cancer. Clin Cancer Res. 2019; 25(16): 5015-5026.

23. Goodman AM, Kato S, Bazhenova L, et al. Tumor Mutational Burden as an Independent Predictor of Response to Immunotherapy in Diverse Cancers. Mol Cancer Ther. 2017; 16(11): 2598-2608.

24. Kowanetz M, Zou W, Shames D, et al. Tumor mutation burden (TMB) is associated with improved efficacy of atezolizumab in $1 \mathrm{~L}$ and 2L+ NSCLC patients. J Thorac Oncol. 2017; 12: S321-322.
25. Roszik J, Haydu LE, Hess KR, et al. Novel algorithmic approach predicts tumor mutation load and correlates with immunotherapy clinical outcomes using a defined gene mutation set. BMC Med. 2016; 14(1): 168

26. [Internet] Genetech.https://clinicaltrials.gov/ct2/show/results/NCT028486 51 ?term $=$ NCT02848651\&draw $=2 \&$ rank $=1$.

27. Blons H, Garinet S, Laurent-Puig P, et al. Molecular markers and prediction of response to immunotherapy in non-small cell lung cancer, an update. J Thorac Dis. 2019; 11(Suppl 1): S25-S36.

28. Johnson DB, Frampton GM, Rioth MJ, et al. Targeted next generation sequencing identififies markers of response to PD-1 blockade. Cancer Immunol Res. 2016; 4: 959-967.

29. Garofalo A, Sholl L, Reardon B, Taylor-Weiner A, AminMansour A, Miao D, et al. The impact of tumor profifiling approaches and genomic data strategies for cancer precision medicine. Genome Med. 2016; 8: 79.

30. Rizvi H, Sanchez-Vega F, La K, et al. Molecular determinants of response to anti-programmed cell death (PD)-1 and anti-programmed death-ligand 1 (PD-L1) blockade in patients with non-small-cell lung cancer profifiled with targeted next-generation sequencing. J Clin Oncol. 2018; 36: 633-641.

31. Samstein RM, Lee CH, Shoushtari AN, et al. Tumor mutational load predicts survival after immunotherapy across multiple cancer types. Nat Genet. 2019; 51(2): 202-206.

32. Hellmann MD, Nathanson T, Rizvi H, et al. Genomic Features of Response to Combination Immunotherapy in Patients with Advanced NonSmall-Cell Lung Cancer. Cancer cell. 2018; 33(5):843-852.

33. Reck M, Rodriguez-Abreu D, Robinson AG, Hui R, Csoszi T, Fulop A, et al. Pembrolizumab versus chemotherapy for PD-L1-positive non-small-cell lung cancer. N Engl J Med. 2016; 375: 1823-1833.

34. Gandhi L, Rodriguez-Abreu D, Gadgeel S, Esteban E, Felip E, De Angelis F, et al. Pembrolizumab plus chemotherapy in metastatic non-small-cell lung cancer. N Engl J Med. 2018; 378: 2078-2092.

35. Paz-Ares L, Luft A, Vicente D, Tafreshi A, Gumus M, Mazieres J, et al. Pembrolizumab plus chemotherapy for squamous non-small-cell lung cancer. N Engl J Med. 2018; 379: 2040-2051.

36. Horn L, Mansfield AS, Szczesna A, et al. First-Line Atezolizumab plus Chemotherapy in Extensive-Stage Small-Cell Lung Cancer. N Engl J Med. 2018; 379(23): 2220-2229.

37. Simsek M, Tekin SB, Bilici M. Immunological Agents Used in Cancer Treatment. Eurasian J Med. 2019; 51(1): 90-94.

38. Mahoney KM, Rennert PD, Freeman GJ. Combination cancer immunotherapy and new immunomodulatory targets. Nat Rev Drug Discov. 2015; 14(8): 561-584

39. Pardoll DM. The blockade of immune checkpoints in cancer immunotherapy. Nat Rev Cancer. 2012; 12(4): 252-264.

40. Samstein RM, Lee CH, Shoushtari AN, et al. Tumor mutational load predicts survival after immunotherapy across multiple cancer types. Nat Genet. 2019; 51(2): 202-206 